\title{
A ORDEM DOMINICANA E A CONSTRUÇÃO DE UMA SOCIEDADE PERSECUTÓRIA: OS CASOS DE MAGIA E HERESIA NA LEGENDA ÁUREA
}

\author{
The Dominican Order and the rise of a Persecuting \\ Society: cases of magic and heresy in the Golden Legend
}

\author{
João Guilherme Lisbôa Rangel* \\ Willian Vidal Reis**
}

\begin{abstract}
Resumo: A partir da tese de Robert Ian Moore acerca da formação da "sociedade persecutória", o presente artigo visa a compreender como a elaboração narrativa referente à magia e a heresia contribuiu para formação desta sociedade. Para tanto, toma-se como referencial a Legenda Áurea, escrita pelo dominicano Jacopo de Varazze na segunda metade do século XIII, em razão de toda popularidade que esta obra alcançou em sua época, bem como nos séculos seguintes.

Palavras-chave: Sociedade Persecutória; Magia; Heresia.
\end{abstract}

\begin{abstract}
Based on Robert lan Moore's thesis on the formation of the "Persecuting Society", this work aims to understand how the narrative constructionof magic and heresy contributed to the formation of such society. The Golden Legend, written by the Dominican Jacopo de Varazze in the second half of the thirteenth century, is taken as reference, on account of the popularity that his work reached in his period, as well as in the following centuries.
\end{abstract}

Keywords: Persecuting Society; Magic; Heresy.

\section{Introdução}

Tanto o termo quanto o conceito de "sociedade persecutória" foram tomados da importante tese defendida por Robert Ian Moore em 1987. Segundo este autor, a partir do século XI, a reforma da Igreja vai progressivamente conferir maior centralidade e autoridade ao poder Papal que repercutirá na repressão às heresias, sobretudo no século XIII com o IV concílio de Latrão (1215), bem como na formação da própria "sociedade persecutória”, que também perseguirá judeus e leprosos (Moore, 1989). Nesse sentido, tal sociedade, mediante o fortalecimento da Igreja, criará para si "inimigos comuns" cujo significado que assumem está diretamente relacionado ao desenvolvimento (do poder) da própria Igreja.

Dando continuidade as investigações acerca da "sociedade persecutória", os trabalhos reunidos por Monique Zerner em "Inventar a heresia?" lançaram luz nesta "construção de inimigos comuns" mediante as manipulações textuais exercida pelas instituições eclesiásticas, isto é, a

\footnotetext{
* Mestre e doutorando em História pelo PPHR-UFRRJ. Bolsista CAPES.O presente trabalho foi realizado com apoio da Coordenação de Aperfeiçoamento de Pessoal de Nível Superior - Brasil (CAPES) - Código de financiamento 001. E-mail: jglhistoria@gmail.com

** Mestrando em História pelo PPGIHS-UFRJ. Bolsista CNPq. E-mail: willian_reis9@hotmail.com
} 
"relação do texto escrito com a verdade e a construção de uma verdade, cuja natureza, (...) muda a partir dos anos de 1180 com o estabelecimento progressivo do procedimento inquisitorial paralelo ao fortalecimento de referência ao direito romano, dominado pela vontade de fazer confessar" (Zerner, 2009, p.9). Em outras palavras, para além das definições doutrinárias/espirituais acerca da heterodoxia, demonstrou-se os aspectos políticos e discursivos em torno do que vem a ser a heterodoxia, bem como os motivos que se leva a perseguição e condenação, ou não, de um grupo num determinado momento histórico.

A relação da Igreja e dos seus com heterodoxias como a heresia (no sentido estrito do termo) e a magia, portanto, se dá de maneira tensionada e contraditória. Ou seja, a maneira a qual a Igreja tratará esses "inimigos" revela não apenas sua "visão" acerca destes, mas sim sua própria transformação institucional. Segundo Alain Boureau, por exemplo, entre os anos de 1280-1330, houve uma "virada demonológica" que ampliará a noção de heresia associando-a a bruxaria (Boureau, 2016). Um aspecto importante presente neste período foi o intenso deslocamento dos inquisidores, sejam eles franciscanos ou dominicanos que ao se reunirem frequentemente nos capítulos provinciais e gerais (Martín, 1995), bem como terem constantes mudanças de cargos dentro das ordens, acabaram dotando as heresias de mobilidade (Boureau, 2008). Paradoxalmente, a intensa circulação de monges dominicanos, por exemplo, exportava o próprio "mal" que eles combatiam.

Desse modo, pretendemos verificar neste artigo, como a Ordem Dominicana, a partir do tratamento dado às heresias (e nisto incluímos a magia e seus praticantes), contribuiu na formação desta "sociedade persecutória". Para tanto, tomaremos como caso específico, a Legenda Áurea, obra escrita pelo dominicano Jacopo de Varazze na segunda metade do século XIII. Esta obra, sem dúvida alguma foi a que mais gozou de sucesso no período medieval (com mais de 1000 manuscritos latinos preservados), além de ter por finalidade primaria, segundo Boureau, a pregação (BOUREAU, 2004, p.30).

\section{Magia e Heresia na Legenda Áurea}

Conforme apontamos nas páginas anteriores, no século XIII os esforços da Igreja Católica encontram seu paroxismo no ocidente. As estratégias adotadas desde o século XI pelo que se denominou convencionalmente de Reforma Gregoriana são frutos de uma série de questões locais determinantes para a sobrevivência da instituição como detentora de bens e almas. Na medida em que os poderes laicos ganhavam autonomia, a Igreja buscava moldar ao mundo e a si em um processo de dupla direção. Em meio a essas tensões, eventos como o IV Concílio de Latrão, em 1215, foram fundamentais para a manutenção da ortodoxia. Além disso, o surgimento das Ordens Mendicantes figura também como um marco no modo como a instituição eclesiástica passou a lidar com o tempo e a sociedade que a circundava e integrava.

A tutela da sociedade exigia ações estratégicas no que diz respeito à comunicação com a comunidade. Nesse sentido, a Ordem Dominicana fora essencial pelo modo como atuava. Segundo André Vauchez, São Domingos entendeu a função da palavra na transmissão e na educação da fé cristã. $\mathrm{O}$ fato de os membros serem sacerdotes contribuiu para que as pregações não fossem puramente penitenciais, mas também para que pudessem abordar questões mais complexas. Os membros desta ordem apoiavam-se na cultura livresca para tornar mais eficaz seu ministério. O trabalho intelectual fora colocado em primeiro plano em relação à liturgia e a vida conventual. A Ordem compreendeu que a mensagem cristã seria mais palpável se apresentada em ideais de humildade e de pobreza. 
Os pregadores, desta maneira, logo se configuraram como despojados de bens imóveis e rendimentos fixos. Contudo, o lugar que estes concediam a pobreza era diferente do que esta ocupava em São Francisco. Para os dominicanos, a pobreza constituía uma arma contra a heresia, além de uma condição, embora não suficiente em si mesma, para que a mensagem dos pregadores fosse recebida e compreendida pelas massas. Desse modo, os dominicanos agiam como bons divulgadores, sensibilizando o clero secular e os leigos, a fim de tê-los sob sua direção espiritual, para as implicações morais relativas à fé (Vauchez, 1995: 153-154).

A busca por uma sociedade tutelada se deu juntamente com a pretensão da Igreja de lutar contra práticas heterodoxas, como as heresias que rondavam a comunidade cristã. Para obter maior coesão social, assim, era interessante para os divulgadores ensinar e admoestar os cristãos acerca do perigo dessas crenças e práticas. Iniciava-se o caminho para a pedagogia do medo analisada por Jean Delumeau em seu clássico livro História do medo no ocidente (Delumeau, 2009). A pregação necessitava criar material para seus objetivos. Esses materiais continham alegorias e histórias sobre os perigos e malefícios presentes no mundo, os quais deveriam ser evitados. Os Dominicanos, mais especificamente, tinham como característica não somente a pregação, mas também a indução desta. No século XIII, portanto, fomentou-se uma série de questões relativas aos temores da ortodoxia que extremaram a preocupação da comunidade em relação à heterodoxia. Os inimigos não somente eram ameaças reais, mas foram, também, eles próprios criados e incorporados no universo da cristandade a partir das construções eclesiásticas.

A Legenda Aurea figura como uma das principais produções do período. Seu conteúdo veiculava, através da tradição dos exempla ${ }^{1}$, mensagens moralizantes e edificantes que serviam como base para sermões em pregações e na evangelização cotidiana(CASAGRANDE). A Legenda Aurea, portanto, fornece material para os estudiosos da Ordem, internamente, e para os pregadores no meio secular. Ao mesmo tempo, seu material condiciona uma leitura que busca enquadrar os valores cristãos dentro da ótica da ordem que a produz. Opera-se uma pedagogia moralizante(Almeida, 2014). No seio da Ordem, uma das preocupações nevrálgicas era justamente a pregação em relação às práticas desviantes. Assim, as narrativas atingem seu objetivo dentro de uma tradição exemplar. As práticas heterodoxas aparecem no documento sempre de maneira a por os santos em confronto, e no exercício de demonstração da força da fé, estes acabam tendo êxito na salvação de si e dos outros.

Além da pretensão da ordem de obter um bom material para seus fins predicantes e formativos, a obra sintetizava, nesse contexto, preocupações da ordem do dia, sendo a heresia um dos fenômenos com aparição frequente (Rangel, 2016). Em um dos primeiros capítulos da Legenda Aurea, dedicado a Santo Antônio, a heresia aparece como um "mal capaz de destruir a Igreja". Já na legenda de São Félix, papa, podemos ler:

\footnotetext{
${ }^{1}$ Segundo Federico Bravo, o exemplum é: "modalidade do discurso didático cuja característica mais notável é, precisamente, a de fazer coincidir em uma só duas artes diferentes: a de ensinar a de contar. Recorrese ao longo da Idade Média, e de forma especialmente intensa a partir do século XIII, professores, oradores, moralistas, místicos e pregadores, para exemplificar e adornar suas exposições, ilustrando-as com todo tipo de fábulas, anedotas, bestiários, relatos históricos, apologéticos, historietas, legendas, etc. De origem sagrada ou profana, tomado do fontes orientais ou ocidentais, improvisado pelo autor ou retirado da tradição popular, da antiguidade clássica e do medievo, o fundo narrativo de que se nutre o discurso didático medieval é ilimitado. Fiç̧ão narrativa concebida para servir de demonstração, o exemplum e, pois, a um tempo, um método didático e um gênero literário" Tradução livre. (Bravo, 1999).
} 
Félix foi eleito e ordenado papa no lugar de Libério. Como o papa Libério não quis aprovar a heresia ariana foi enviado por Constâncio, filho de Constantino, para o exílio, onde permaneceu três anos. Foi por isso que todo clero romano ordenou Félix para seu lugar, seguindo a vontade do próprio Libério. Quando de sua eleição, Félix convocou um concílio com 48 bispos e condenou Constâncio, imperador ariano herético, e dois presbíteros que o apoiavam. Indignado, Constâncio destituiu Félix do episcopado e revogou o exílio de Libério, com a condição de ele concordar com as ideias do imperador e de todos que Félix havia condenado. Afetado pelo tédio do exílio, Libério subscreveu o erro da heresia e desta forma cresceu a perseguição a muitos sacerdotes e clérigos, assassinados dentro da Igreja sem que Libério o impedisse. (Varazze, 2003:585)

O resultado da retirada de Félix é a perseguição de sacerdotes e clérigos dentro da Igreja. Novamente, verificamos que a heresia é um mal para a instituição eclesial que afeta sua liberdade. Mais adiante, no capítulo de Santo Eusébio, a mesma situação é observada:

Como naquele tempo a peste ariana infectava toda a Itália, com o imperador Constâncio sendo favorável aos heréticos, o papa Juliano sagrou Eusébio bispo de Vercelli, que era então uma das principais cidades da Itália. Sabendo disso, os heréticos quiseram fechar todas as igrejas. Eusébio entrou na cidade, ficou de joelhos na entrada da principal igreja, dedicada à bemaventurada Maria, e logo todas as portas abriram-se à sua prece. Ele expulsou de seu episcopado Maxêncio, bispo herético de Milão, e para seu lugar ordenou Dionisio, ilustre católico. Desta forma Eusébio purificou da peste ariana toda a Igreja do Ocidente, como fazia Atanásio com a Igreja do Oriente. (Varazze, 2003:597)

A primeira atitude dos heréticos ao saberem da sagração de Eusébio é fechar todas as Igrejas. Entretanto, mediante a atuação do santo, o inverso acontece e a heresia é derrotada. Fato interessante é que nesta legenda a heresia também é tratada apenas pelo nome, além de ter sua história apresentada por Jacopo. O dominicano aponta que a mesma veio de Ário e que ele "afirmava ser Cristo uma simples criatura feita por Deus para servir de instrumento quando Ele nos criasse" (Varazze, 2003:597). Os arianos negavam a natureza divina de Cristo e sua consubstanciação a Deus pai. Mais a frente, Jacopo vai demonstrar que com o concílio de Nicéia (325), o dogma da natureza divina de Cristo foi afirmado e, o "erro" ariano, condenado. Todavia, o imperador Constâncio havia se convertido ao arianismo e continuava a imputar dificuldades à "verdadeira" Igreja.

Nas passagens referentes às heresias, sobretudo quando o arianismo é mencionado, percebemos que para além do mal que a heresia é capaz de fazer à Igreja, a interferência do poder temporal, nesse caso do Imperador, nos assuntos eclesiásticos também é questionada. Podemos verificar isso na legenda de São Basílio:

O imperador Valente, defensor do arianismo, tirou uma igreja dos católicos para dá-la aos arianos. Basílio foi ter com ele e disse: "Imperador, está escrito: 'A majestade real brilha no amor à justiça. O julgamento do rei é a justiça'. Por que, então você ordenou de livre e espontânea vontade que os católicos fossem expulsos dessa igreja e que ela fosse entregue aos arianos?" O imperador respondeu: "Basílio, não é conveniente que me fale assim". Ele replicou: "Não me importo de morrer pela justiça". Então o cozinheiro-chefe do imperador, chamado Demóstenes, partidário dos arianos, tentou intervir, mas Basílio disse-lhe: "Sua tarefa é cuidar dos guisados do imperador, e não resolver questões de fé", o que o deixou confuso e o fez calar-se. Disse então o imperador: "Basílio, vá e arbitre o problema entre os dois partidos, mas sem se deixar influenciar pelas opiniões do povo".

Ele propôs a católicos e arianos que se mandasse fechar as portas da igreja, nelas colocar os selos de cada um dos partidos, e aquele que conseguisse abrir as portas através de preces teria a posse da igreja. A proposta foi aceita por todos. Os arianos rezaram durante três dias e três 
noites, e quando chegaram diante das portas da igreja elas não estavam abertas. Então Basílio, à frente de uma procissão, foi até a igreja e, depois de ter feito uma prece, tocou levemente as portas com seu cajado pastoral dizendo: "Deixem o caminho livre, poderes celestes, abramse, portas eternas, a fim de deixar entrar o rei da glória". E imediatamente as portas abriramse, todos entraram dando graças a Deus, e a igreja ficou novamente na posso dos católicos. (Varazze, 2003:193)

A heresia ariana retira uma igreja das mãos dos católicos. Além desse mal causado por ela, podemos observar que a interferência do Imperador Valente é nociva para a Igreja visto que este não apenas chancela a retirada da igreja, como também tenta se colocar superior "a justiça" (divina). Um acontecimento semelhante se dá na legenda de São Bento, em que um rei godo, herético ariano, perseguia com crueldade os religiosos da Igreja (Varazze, 2003:302) e, também, na legenda de Santo Ambrósio, na qual lemos dois aspectos esclarecedores acerca da virtude desse santo:

Um, a defesa da verdade católica. Como está no livro XI da História eclesiástica, Justina, discípula dos arianos e mãe do imperador Valentiniano, tentou conturbar a Igreja ameaçando com o exílio os padres que não concordassem em revogar os decretos do concílio de Rimini, forma de atacar Ambrósio, muralha e torre da Igreja. Ė o que mostra o prefácio da sua missa: "Ó Senhor, você fortaleceu Ambrósio com tanta virtude, ornou-o com uma constância celeste tão admirável, que ele atormenta e expulsa os demônios, confunde a impiedade ariana, submete humildemente a seu julgo os príncipes seculares".

Dois, a defesa da liberdade da Igreja. O imperador desejava apoderar-se de uma basílica, mas Ambrósio resistiu, como ele o próprio atesta, e suas palavras estão reproduzidas no Decreto XXIII, questão 6: Uns condes pressionaram-me a abandonar a basílica dizendo que era ordem do imperador e que eu devia entregá-la porque ele tinha direito a ela. Respondi que: "Se o que ele pede for meu patrimônio, peguem, se for meu corpo, irei oferecê-lo. Querem me prender? Prendam-me Querem minha morte? Também a quero. Não recorrerei à multidão para me defender, não me refugiarei no altar, mas de bom grado me deixarei imolar. Vocês me dão a ordem monárquica de entregar a basílica, mas a ela contraponho as palavras da Escritura. Você fala como um insensato, imperador, se pensa ter qualquer direito sobre as coisas divinas. Ao imperador, os palácios, aos padres, as igrejas. São Nabot defendeu sua vinha com sangue, e se ele não cedeu uma vinha, por que cederíamos a igreja de Cristo? O tributo pertence ao césar, e ninguém deve recusá-lo. A igreja pertence a Deus, e não pode ser entregue ao césar. Se me pedissem, se me forçassem, a dar terras, casa, ouro ou prata, enfim qualquer coisa que me pertencesse, eu a entregaria de bom grado, mas não posso tirar nada do templo de Deus, pois eu recebi para conservá-lo, não para dilapidá-lo. (Varazze, 2003:362)

Defensor da Igreja, a legenda de Ambrósio corrobora nossa argumentação de como a heresia é entendida na Legenda Áurea, ou seja, um mal que ataca a verdadeira fé católica, ameaçando seus templos e sua liberdade. A heresia pode ser tão nociva, que o próprio poder temporal convertido a ela pode contribuir para a destruição da Igreja, por isso, é necessário que ele não interfira nas decisões eclesiásticas. Todavia, se ainda assim este intervir, a ação divina em prol da Igreja testifica a autoridade desta última em detrimento dos demais.

Outro capítulo que deixa evidente nossa argumentação é um dos mais notáveis da obra do dominicano de Varazze, a saber: o de Pedro Mártir, primeiro dominicano mártir a ser canonizado:

Como na província da Lombardia e em diversas outras cidades, a peste herética e diabólica contagiava muita gente, visando destruí-la o sumo pontífice enviou a diversas partes da Lombardia vários inquisidores da ordem dos frades pregadores. Mas como em Milão os hereges, numerosos e apoiados pelo poder secular recorriam a uma eloquência fraudulenta e a uma ciência diabólica, o sumo pontífice enviou para lá como defensor da fé e inquisidor com plenos 
poderes o beato Pedro, por conhecer sua grandeza, seu destemor diante de uma multidão de inimigos, sua coragem inabalável que o fazia não ceder nem mesmo em pequenas coisas diante da força dos adversários, sua eloquência que desmascarava com facilidade as artimanhas dos heréticos, sua sábia erudição das coisas divinas, que lhe permitia refutar racionalmente os argumentos heréticos. (Varazze, 2003:390)

Esta breve citação nos fornece fartos elementos para análise. Por exemplo, a menção à província da Lombardia a qual Jacopo foi prior, ou até mesmo, a valorização dos elementos "eruditos e racionais" para confrontar a argumentação herética. Contudo, o que nos interessa aqui, é o reconhecimento apresentado no texto de que os "heréticos" recebiam apoio "secular", ou seja, um apoio capaz de opor a autoridade da Igreja e, consequentemente, sua própria liberdade.

Mediante esta relação estabelecida pela obra de Varazze da heresia como "um mal capaz de destruir" a Igreja visto que atenta contra sua liberdade, os dominicanos contribuíram para a construção deste "inimigo comum" alvo e ao mesmo tempo "força propulsora" desta sociedade persecutória. Não a toa, Monique Zerner vai afirmar que: "a história da heresia seguiu a evolução do poder" (Zerner, 2006:503), visto que desde de Constantino, sobretudo após o estabelecimento do cristianismo como religião lícita, a heresia se ligou a história do Estado, tendo perseguido todo aquele que rejeitava a ortodoxia dos pais da Igreja. Este também será os casos de magia e seus praticantes presentes na Legenda Aurea.

Segundo Kieckhefer, a condenação à magia pelo Cristianismo ganhou força ao final da Antiguidade, através dos escritos dos Padres da Igreja(Kieckhefer, 2002: 47-79). Os discursos que germinaram nesse contexto foram apropriados e reproduzidos no seio da tradição cristã nos séculos posteriores, até, pelo menos o século XIII, no qual se operou uma virada demonológica, surgida no seio das reflexões Escolásticas preocupadas com a relação entre feitiçaria e o contato demoníaco (Boureau, 2016). O padrão descritivo, ou seja, a forma pela qual a detração de heréticos e mágicos se dava, nos escritos cristãos, compartilhava protocolos bastante comuns entre si, e sua reprodução fora perpetuada (Peters, 1978: 12). Entretanto, os casos de heresia e magia na Legenda Aurea são narrados de maneiras relativamente distintas. Enquanto a primeira figura como uma ameaça de destruição da comunidade, os confrontos com os mágicos chamam a atenção para a potência da crença e dos poderes cristãos frente aos prodígios realizados por adeptos das artes mágicas. Constituída por um largo apanhado de incorporação de hagiografias, narrativas históricas, escritos teológicos, a Legenda Aurea não contém originalmente muitos dos discursos que a atravessam, mas os incorpora (Boureau, 1984). Algumas dessas formulações estavam presentes anteriormente no pensamento cristão, particularmente o modo como se descreve a magia.

Em relação aos padrões representativos da magia, a maioria dos casos narrados na coletânea hagiográfica de Jacopo de Varazze está em consonância com os discursos formulados no período patrístico, embora nem sempre se manifestem incorporando todos os elementos. Segundo David Collins, uma das representações paradigmáticas do modo como o cristianismo lida com a magia e a descreve está em Agostinho de Hipona, o qual desenvolveu uma influente distinção entre milagre e magia. Em sua avaliação, milagres eram inspirados por Deus, o qual conduzia os perseverantes à fé. Ao contrário, a magia se dava apenas por meio do envolvimento com demônios e não incluía qualquer fortalecimento de fé em seus efeitos. A distinção de Agostinho recaia primeiramente na agência do ato, e secundariamente no interior dos efeitos, como o aumento de fé. Assim, essa distinção minimiza o significado de efeitos observáveis, como o fato de um doente ter sido curado etc., uma vez que demônios poderiam provocar eventos na natureza para fins malignos. Agostinho extinguiu, portanto, a distinção entre magia lícita e ilícita, pois, uma vez que definiu seu agente 
como demoníaco, ela é vista como imoral e proibida (Collins, 2011: 411).

$\mathrm{Na}$ legenda de São Pedro, Apóstolo, está narrado o encontro deste com uma figura conhecida por ser um dos maiores arquétipos representativo do mágico, Simão, o mago. O encontro entre as personagens se dá em confrontos nos quais cada um busca provar seu poder em detrimento do outro. Em vários momentos eles disputam a fim de provar o valor de seus poderes. Esses trechos contêm descrições interessantes para vislumbrar o modo como a narrativa opera. $\mathrm{Na}$ aparição de Simão, podem-se retirar alguns elementos importantes para a compreensão do quadro caracterizante do mágico. Conta-se que o mago se dizia Deus, e que isto fora acreditado pelo imperador romano pela sua troca de fisionomia. Em seguida, utiliza-se de um artifício descrito como "ilusão da arte mágica".

Em seguida, conta-se que um demônio assumira sua forma, o que o fazia estar em dois lugares. Paulo e Pedro foram ao encontro de Nero e disseram que em Simão havia a substância do homem e do diabo, comparando-o com a substância de Deus e de homem em Jesus. E quando Simão ameaçou expulsá-lo com anjos, o apóstolo o desafiou a adivinhar o que pensava. Em seguida, Simão invocou cães que se lançaram sobre Pedro, o qual mostrou-lhes um pão bento que acabara de abençoar e os expulsou (Varazze, 2003: 503). Em seguida, há um confronto em relação à ressurreição.

[...] Depois, contam Hegésipo e Lino, inchado de soberba Simão jactou-se de poder ressuscitar mortos. Como um rapaz acabara de morrer, chamaram Pedro e Simão e todos unanimemente aceitaram a sugestão de Simão de que, quem não pudesse ressuscitar o morto, seria por sua vez morto. Enquanto Simão fazia seus encantamentos sobre o cadáver, os presentes tiveram a impressão de ver a cabeça do defunto mover-se. Todos passaram então a gritar e a querer lapidar Pedro, que mal pôde conseguir silêncio para dizer: "Se o morto está vivo, que levante, que ande, que fale, caso contrário mexer a cabeça do cadáver é fantasmagoria. Que Simão fique afastado do leito do morto para que as artimanhas do diabo sejam plenamente desmascaradas". Afastaram Simão do leito e o rapaz permaneceu imóvel. Pedro, à distância, fez uma prece e depois disse em voz alta: "Rapaz, em nome de Jesus Cristo, o nazareno, que foi crucificado, levante e ande". E no mesmo instante ele se levantou, vivo, e andou. O povo queria lapidar Simão, mas Pedro falou: "Ele já foi devidamente punido vendo seus artifícios serem superados. Ademais, nosso mestre ensinou-nos a responder o mal com o bem" (Varazze, 2003: 504-505).

Nessa história, o feito de Simão é desmascarado por Pedro, uma vez que não passa de uma tentativa de farsa. Assim, enquanto o primeiro figura como charlatão, o segundo obtém êxito na realização do milagre. Em todas as tentativas, Simão é superado pelos feitos de São Pedro. A narrativa constrói uma imagem de que mágicos como detentores de crenças que não lhe permitem intervirem no mundo com a mesma potência que os santos cristãos, que gozam do apoio de Deus. As passagens do encontro de Simão e Pedro demonstram algumas associações comuns operadas no discurso cristão: a associação dos praticantes de magia ao diabo, a descrição dos feitos como "ilusões", e a maior força dos prodígios cristãos frente aos dos mágicos. Desse modo, mesmo quando as mágicas de Simão aparentemente funcionavam, eram ilusões ou o se faziam pelo auxílio do diabo.

No caso de São Jorge, conta-se que após salvar a filha do rei de Silena, cidade província da Líbia, de um dragão, soube da matança de cristãos promovida pelos imperadores romanos Diocleciano, Maximiano e Daciano, convertendo-se às vestes cristãs e dizendo "todos os Deuses gentios são demônios, foi o senhor que fez os Céus” (Varazze, 2003: 268). Ao ouvir tais palavras, o governador pediu que o torturassem, mas seus ferimentos foram curados por Deus. 
Percebendo que não podia dobrá-lo com torturas, Daciano convocou um mágico, a quem disse: "Graças às artes mágicas, os cristãos zombam dos tormentos e recusam-se a sacrificar a nossos deuses" O mágico respondeu: "Se não conseguir superar seus truques, que eu perca a cabeça!". Preparou então seus feitiços, invocou seus deuses, misturou veneno com vinho e deu-o para São Jorge beber. O homem de Deus fez sobre a bebida o sinal-da-cruz e tomou-a sem ser afetado. O mágico preparou uma dose mais forte, que o homem de Deus bebeu inteiramente, sem dano algum, após ter feito o sinal-da-cruz. Ao ver isso, o mágico lançou-se aos pés de Jorge, chorando, arrependido, e pediu para ser cristão. Logo depois o juiz mandou decapitá-lo (Varazze, 2003: 368).

Aqui, nota-se que Daciano relaciona a resistência de São Jorge às “artes mágicas". Mas ao contratar um mágico, este não obtém sucesso na tentativa de envenenamento operada e busca a conversão. Nesta passagem, demonstra-se mais uma vez a força dos servos de Deus frente aos feitos de seus inimigos, nesse caso, necessariamente por uma competição de prodígios, mas por um exercício de resistência do santo ao veneno do mágico. Nesse caso, a virtude do representante cristão supera as tentativas de realização das atividades mágicas, as quais se mostram impotentes. Há também o estopim da prisão de Jorge: a pregação contra os deuses dos gentios, associados a demônios. Após resistir a outras tentativas de prejuízo a ele, Daciano aponta que seus deuses estavam sendo mansos com Jorge, e seriam indulgentes em caso de conversão. Além disso, Daciano pedia para o santo abandonar suas "superstições". Jorge diz que se converterá ao que segue o relato:

Iludido por essa fala, Daciano, muito feliz, mandou o pregoeiro público convocar a todos para ver Jorge, por tanto tempo rebelde, enfim ceder e sacrificar aos deuses. A cidade inteira foi engalanada e com alegria esperou o momento, mas ao entrar no templo para sacrificar aos ídolos, Jorge ajoelhou-se e pediu ao Senhor que destruísse completamente o templo com seus ídolos. No mesmo instante caiu o fogo do Céu sobre o templo, queimando-o com seus deuses e seus sacerdotes. A terra entreabriu-se e tragou tudo o que restara.(Varazze, 2003: 369).

Nos dois casos analisados, manifestam-se alguns lugares comuns marcantes no discurso cristão durante a Idade Média, em diversos setores de sua produção, como os exempla e as narrativas históricas (Kieckhefer, 2002). A "competição" de potências é marcada aí por elementos como as representações do mal, como o diabo ou as outras divindades, demonizadas - sempre relacionados aos inimigos dos santos. A apresentação dessas características e dos personagens que as servem são, então, segundo o padrão narrativo da obra, seguidas de suas superações pelos feitos dos santos, que os sobrepujam com realizações verdadeiras ou a resistência às tentativas de causar-lhes danos.

Assim, no caso das narrativas acerca dos mágicos e da magia na Legenda Áurea, a figura do mágico aparece como um contraponto a fé e os valores cristãos, além de configurar um desafio mesmo à potência dos poderes dos representantes do cristianismo (tal como a heresia). A figura do mágico é detraída nesses confrontos, geralmente com vitórias dos santos por meio dos milagres. A afirmação do santo se faz pelo contraste com os poderes dos mágicos. Nesse sentido, o trabalho de Santiago Catellanos chama nossa atenção ao perceber o uso de determinados personagens marginais nas narrativas como carregado de intencionalidades que tocam menos em uma realidade exterior aos documentos do que em objetivos centrais destes escritos. Assim, muitas vezes algumas figuras são inseridas para dar ainda mais protagonismo ao herói, o qual mostra suas virtudes por meio da interação com elas (Castellanos, 2013: 279-292). 


\section{Conclusão}

As hagiografias da Legenda Áurea, assim, ao apresentar um discurso moralizante exemplar, fixam determinados ideais de conduta e salvação os quais, ainda que produzidos no sentido de legitimar a Ordem Dominicana, produzem discursos de exclusão de ideias e práticas por meio de estratégias narrativas de estigmatização e detração. Tanto a heresia, quanto a magia figuram na obra de modo emblemático, contribuindo para a circulação e consolidação das representações de práticas heterodoxas requerida para a solidificação do poder eclesial no ocidente.

Não à toa, conforme mencionado, ainda no século XIII o alargamento da heresia abrange a questão da magia e da bruxaria, abrindo margem para os eventos posteriores da sociedade persecutória (Moore, 1989). Os empreendimentos aos quais se lançaram as Ordens Mendicantes, em especial a Dominicana, para evangelização e defesa da comunidade cristã se utilizaram, desta forma, de uma pedagogia moral que apelava para a construção de padrões de santidade que serviam como espelhos virtuosos de boa conduta rumo à salvação.

Ao mesmo tempo, os elementos narrativos e discursivos mobilizados nas narrativas exemplares, que tinham os santos como protagonistas e modelos, apelavam à detração de inúmeros outros inimigos para servirem como um modelo do que não se deve crer/praticar, uma vez que tais personagens, representativos de determinados valores e atos, se enquadravam na narrativa sempre de maneira negativa, representando perigos à comunidade, ou mesmo agindo de maneiras imorais e anticristãs. Ainda que as hagiografias não tivessem como finalidade uma descrição fidedigna de uma realidade, seus usos são dotados de intencionalidades que excluem forças e personagens, induzindo os leitores ou ouvintes a internalizarem condutas e crenças, a depender do escopo de quem as mobiliza.

O poder da Igreja, portanto, necessitou criar inimigos e perigos para se consolidar frente à comunidade como provedora de proteção. No limite, como afirmou Monique Zerner, "a heresia existe onde a Igreja quer que ela exista"(Zerner, 2006:517), posto que mediante operação narrativa, tal qual a realizada na Legenda Aurea, a heresia e a magia (bem como o herético e o mago) são dotadas de coerência e finalidade que, não raro, escapam seus próprios objetivos internos. Assim, parafraseando Moore: enquanto o poder é um fato, autoridade é construída, e para sua construção o desvio é quase um aliado (Moore, 2007: VIII). Nesse sentido, tanto a heresia quanto a magia foram "aliadas" na construção da autoridade da Ordem Dominicana e, por consequência, da própria Igreja e da "sociedade persecutória".

\section{Fontes:}

lacopo da Varazze Legenda Aurea. Ed. G. P. Maggioni, Firenze: Galuzzo, 1998.

VARAZZE, Jacopo. Legenda Áurea. Vidas de Santos. Trad. Hilário Franco Jr. São Paulo: Cia. das Letras, 2003.

\section{Bibliografia:}

ALMEIDA, Neri de Barros. Hagiografia, propaganda e memória histórica. 0 monasticismo na Legenda Aurea de Jacopo de Varazze. Revista Territórios \& Fronteiras, Cuiabá, vol. 7, n.2, jul.-dez., 2014 pp.94-111. 
BOUREAU, Alain. Introduction .VORAGINE, JACQUES. La Légende Dorée. Text traduit, presente et anoté par Alain Boureau, Pascal Collomb, Monique Goullet, Laurence Moulinier et Stéfano Mula. Paris: Gallimard, 2004. Pp.XV- XLVIII.

. La circulation des hérésies dans l'Europe médiévale. Les Cahiers du Centre de Recherches Historiques, 42, 2008 pp.19-30. Disponivel em: http://ccrh.revues.org/3421.

Satã Herético. 0 nascimento da demonologia na Europa medieval (1280-1330). Campinas: Editora da Unicamp, 2016.

. La Légende dorée. Le système narratif de Jacques de Voragine (1298), Paris, Cerf, 1984.

BRAVO, Federico. Arte de enseñar, arte de contar. Em torno al exemplum medieval. In. La enseñanzaenlaEdadMedia. X Semana de EstudiosMedievales, Nájera 1999 Disponível em: http://www.vallenajerilla.com/berceo/bravo/exemplum.htm. Acessado em:25/02/2019.

CASAGRANDE, Carla. La vie et les oeuvres de Jacques de Voragine. Sermones. net. http://sermones.net/content/la-vie-et-les-oeuvres-de-jacques-de-voragine-op. Acessado em: 25/02/2019.

CASTELLANOS, Santiago. Marginados enlasVitae de lahagiografía visigoda. In: GONZÁLEZ SALINERO, Raúl (ed.). Marginados Socialesy ReligiososenlaHispaniaTardorromana y Visigoda. MadridSalamanca: SigniferLibros, p. 279- 292, 2013.

COLLINS, David J. Magic in the Middle Ages: History and Historiography. HistoryCompass, Washington, v. 9/5, s/n, p. 410-422, 2011.

DELUMEAU, Jean. História do medo no ocidente 1300-1800: uma cidade sitiada. São Paulo: Companhia das Letras, 2009.

KIECKHEFER, Richard. A Magia na Idade Média. Lisboa: Temas e Debates: 2002.

MARTÍN, BonifacioPalacios. Los dominicos y lasórdenes mendicantes enlesiglo XIII. VI Semana de EstudiosMedievales. Nájera, 1995

MOORE, R. I. La formación de uma sociedad repressora: poder y dissidência em la Europa occidental, 950-1250. Editorial Crtítica: Barcelona, 1989.

The formation of persecution society: authority and deviance in Western Europe, 9501250. Segunda Edição. Melbourne: BlackwellPublishing, 2007.

PETERS, Edward. The Magician, the Witch and the Law. Philadelphia: University of Pensilvania Press, 1978.

RANGEL, João Guilherme Lisbôa. Pregação e História: os casos de heresia na Legenda Áurea (c. 1270-1298).Seropédica, ICHS-PPHR- UFRRJ, 2016, Dissertação de mestrado disponível em: (https://tede.ufrrj.br/jspui/handle/jspui/1708?mode=full\#preview-link0 )

VAUCHEZ, André. A Espiritualidade na Idade Média Ocidental. Séc. VIII - XIII. Lisboa: Estampa, 1995.

ZERNER, Monique (Org). Inventar a heresia?discursos polêmicos e poderes antes da Inquisição. Campinas, SP: Editora da Unicamp, 2009.

“Heresia”. LE GOFF, Jacques, SCHIMITT, Jean-Claude (org.). Dicionário Temático do Ocidente Medieval. Vol I. São Paulo: EDUSC, 2006. pp 503-521.

Artigo recebido em: 28/02/2019

Artigo aceito em: 06/05/2019 